\title{
A role of stretch-activated potassium currents in the regulation of uterine smooth muscle contraction
}

\author{
lain L O BUXTON* , Nathanael HEYMAN, Yi-ying WU, Scott BARNETT, Craig ULRICH \\ Myometrial Research Laboratory, University of Nevada School of Medicine, Reno, Nevada 89557-0573, USA
}

\begin{abstract}
Rates of premature birth are alarming and threaten societies and healthcare systems worldwide. Premature labor results in premature birth in over $50 \%$ of cases. Preterm birth accounts for three-quarters of infant morbidity and mortality. Children that survive birth before 34 weeks gestation often face life-long disability. Current treatments for preterm labor are wanting. No treatment has been found to be generally effective and none are systematically evaluated beyond $48 \mathrm{~h}$. New approaches to the treatment of preterm labor are desperately needed. Recent studies from our laboratory suggest that the uterine muscle is a unique compartment with regulation of uterine relaxation unlike that of other smooth muscles. Here we discuss recent evidence that the mechanically activated 2-pore potassium channel, TREK-1, may contribute to contraction-relaxation signaling in uterine smooth muscle and that TREK-1 gene variants associated with human labor and preterm labor may lead to a better understanding of preterm labor and its possible prevention.
\end{abstract}

Keywords: stretch-activated potassium currents; preterm labor; uterine muscle; nitric oxide; arachidonic acid; pregnancy; TREK-1

Acta Pharmacologica Sinica (2011) 32: 758-764; doi: 10.1038/aps.2011.62

\section{Introduction}

Preterm labor and delivery of an under-developed fetus affect approximately 13 million births worldwide each year ${ }^{[1]}$. The number of babies that die annually due solely to their prematurity ranges from $20000(4 \%)$ in the US to 336000 of the 1.2 million newborn deaths $(28 \%)$ in Sub-Saharan Africa ${ }^{[2]}$. Those that survive their prematurity have numerous chronic health disabilities that constitute a major human tragedy, are enormously costly to societies and cripple the third world development. Advanced medical care makes it possible for premature fetuses (some as early as 22-24 weeks) to survive, but at huge cost often resulting in life-long disability for survivors. Prematurity, whether due to infection or occurring spontaneously, threatens global health and must be addressed.

Despite decades of interest, the majority of cases of preterm labor are unexplained, and there is currently no effective medication to prevent uterine contractions at the time of labor as evidenced by a lack of an FDA approved indication in the US for any treatment for preterm labor (PTL). Challenging also is the absence of a useful animal model in which to propose studies for PTL since there is no animal that experiences this uniquely human problem. The impact of delivery of a pre-

\footnotetext{
* To whom correspondence should be addressed.

E-mail ibuxton@medicine.nevada.edu

Received 2011-03-16 Accepted 2011-04-18
}

mature fetus on society is very high; the Institute of Medicine estimates that this costs the American economy $\$ 26.2$ billion annually (in 2006 dollars).

In the last several years it has become clear that uterine smooth muscle mechanisms of relaxation differ significantly from those of other human smooth muscles. In this review we explore the nature of contractile regulation of myometrial smooth muscle and describe a channel target that we posit may be of significant interest as a therapeutic target for tocolysis.

\section{The onset of labor}

The signal(s) that initiate labor at term in women are unknown. This is an embarrassing truth when viewed in the context of what we have learned in a relatively short time about diseases such as AIDS. Our current ability to treat HIVAIDS with highly active antiretroviral therapy has drastically changed HIV infection from an acute, very deadly disease, to a chronic, long-lasting, manageable disease ${ }^{[3]}$. Such truth offers lessons; among the truths is that targeted research funding can yield results rapidly and the embarrassment surely is that we still don't understand our own reproductive physiology very well.

Theories of the proximate cause of labor have varied over time as we have learned more about what is not, rather than what is responsible for the regulation of uterine contractions. 
For example, quite logical might be the notion that maternal nervous regulation initiates labor. However, we have known for some time that the uterus becomes essentially denervated during gestation ${ }^{[4]}$ and as a result, it is unlikely that any coordinated nervous regulation of the myometrium is centrally orchestrated $^{[5]}$. As a result, views of the origin of onset of labor turned early on to examine endocrine and paracrine mechanism of myometrial regulation. A role for corticotrophin releasing hormone (CRH) posits that the hormone, generated in the placenta, builds in the serum and amniotic fluid as pregnancy progresses ${ }^{[6]}$. The human fetus also has a pituitary-adrenal axis by mid-trimester and $\mathrm{CRH}$, although present in lower concentrations than in the maternal circulation, stimulates adrenocorticotropic hormone (ACTH) secretion from the fetal pituitary. ACTH is also synthesized in the placenta under the influence of $\mathrm{CRH}^{[7]}$. Fetal ACTH stimulates production of the androgenic steroids dehydroepiandrosterone (DHEA) and dehydroepiandrosterone sulphate (DHEAS). Cortisol secretion is induced by ACTH and an increase in fetal cortisol production in late pregnancy is responsible for fetal organ maturation including lung maturation ${ }^{[8]}$. DHEA and DHEAS production in the fetus is thought to lead to initiation of parturition through their metabolism by the placenta to estrogen ${ }^{[9]}$, which acts on the myometrium, cervix and fetal membranes. While estrogen is thought to up-regulate the expression of myometrial genes associated with contraction ${ }^{[10]}$, it is progesterone that is thought to modulate parturition timing through its withdrawal. In a number of animal models, progesterone disappearance from the circulation is associated with onset ${ }^{[11]}$. However, maternal progesterone levels in the blood stream do not fall at the time of onset in humans and so research has focused on the notion of changes in progesterone locally in the uterine compartment not reflected in the maternal circulation such that progesterone withdrawal could occur due to local progesterone metabolism ${ }^{[12]}$ or receptor-based heterologus regulation of steroid hormone receptors that leads to a functional withdrawal of the action of progesterone as recently reviewed by Mitchell and Taggart ${ }^{[13]}$. Whatever the fact of progesterone withdrawal, it is not at all clear that administering progesterone exogenously will serve as an effective treatment of preterm labor ${ }^{[14]}$.

\section{Quiescence is key}

Relaxation of the myometrium is required for pregnancy to proceed in the face of ever increasing tension on uterine muscle as the fetus grows ${ }^{[15,16]}$. Approaches to understanding PTL have examined the notion that there is an inappropriate activation of contractile influences that initiate labor too soon, as well as a failure of relaxation influences on the myometrium $^{[17-19]}$. While both may operate, we assert that successful therapeutic intervention will come from probing relaxation mechanisms. This assertion is supported by the finding that the first drug designed specifically for preterm labor, Tractocile ${ }^{\circledR}$ (atosiban) that blocks the actions of oxytocin (OT), is not superior to conventional approaches to the treatment of preterm labor ${ }^{[20,21]}$, albeit it may pose fewer side effects and is only evaluated at $48 \mathrm{~h}$. This agent is not yet FDA approved in the US. Examination of its development reveals the unimaginative model of an OT receptor blocker to block the actions of $\mathrm{OT}^{[22]}$. In humans however, labor is not just the result of stimulation of the myometrium by oxytocin ${ }^{[23]}$.

\section{NO-mediated relaxation}

Nitric oxide (NO) is particularly effective in relaxing the myometrium and in fact has a lower inhibitory concentration $50 \%\left(K_{\mathrm{i}}\right)$ in human than guinea pig or non-human primate myometrium $^{[24]}$. We have examined the heretical notion that relaxation of the myometrium by $\mathrm{NO}$ is independent of cGMP elevation as a result of soluble guanylyl cyclase. Although this notion was initially rejected by many on the basis that the dogma established by the 1998 Nobel for Physiology or Medicine $^{[25]}$ demanded that NO signals through cGMP in smooth muscle, it is now clearly established from our work and that of others that NO-mediated relaxation of uterine muscle is independent of global cGMP elevation no matter whether this is studied in animal ${ }^{[26]}$, primate ${ }^{[27]}$ or human ${ }^{[28]}$.

Cyclic GMP is not without effect however. When the uterus is relaxed by uroquanylin, cGMP elevation secondary to activation of the guanylyl cyclase activity of the uroguanylin receptor, particulate guanylyl cyclase type $\mathrm{C}$ does relax the uterus. The presence of a uroguanylin-particulate cyclasecGMP relaxation pathway in myometrium taken together with the failure of soluble cGMP elevation to relax the muscle leads to the inevitable conclusion that cGMP is compartmented in the myometrium ${ }^{[29]}$.

The importance of the fact that an effect of NO to relax the uterus is independent of global cGMP accumulation is twofold. First, data supporting the cGMP-independence of nitroagent mediated relaxation of uterine muscle that were first introduced by the pioneering work of Jack Diamond ${ }^{[30-32]}$ and later by our lab as cited above, establish more dramatically than any other type of study we are aware of that the uterus, particularly the human uterus, is regulated in a disparate manner compared to other smooth muscles ${ }^{[19,29]}$.

The notion that the uterine smooth muscle biochemistry of relaxation signaling is fundamentally different than vascular or gastrointestinal muscle means that there is hope for discovery of therapeutic targets in the myometrium that are absent or disparately regulated in other smooth muscles and thus, can permit a reasoned line of investigation to find uterine-specific tocolytics. Whatever is learned must impact the final mediator of muscle contraction, calcium availability in the uterine myocyte and while beyond the scope of this perspective, the reader is guided to a recent expert review ${ }^{[33]}$.

The second point highlighted by the unique nature of NOmediated relaxation of uterine muscle is that since $\mathrm{NO}$ relaxes uterine smooth muscle, NO must act in a fashion other than through activation of the soluble guanylyl cyclase. Thus, NO must directly nitrosylate or indirectly modify one or more proteins in the myometrium that regulate relaxation. Our interest that a stretch-activated potassium channel (K2P) may play a role in normal myometrial relaxation is peaked by the persua- 
sive model that gestational growth means continual myometrial stretch along with the possibility that K2P channels, or their expression is(are) a target for $\mathrm{NO}$ or consequences of $\mathrm{NO}$ signaling.

The notion that NO is generated in myometrium and responsible for regulation of uterine quiescence has been controversial $^{[19]}$ and yet high levels of myometrial expression of nitric oxide synthase(s) correlated with gestation until the time of labor need not be the only source of NO to affect the myometrium. Indeed, recent studies have examined the presence of NO-synthase (NOS) in uterine tissues including myometrium $^{[34]}$ and actions of $\mathrm{NO}$ in reproductive tissues suggest its critical role in normal reproduction ${ }^{[35]}$. A source for myometrial NO may not come from smooth muscle generation directly, but rather from the ability of NO generated in the uterine membranes or the vasculature to bind free cysteine forming cysteine-NO (Cys-NO) or hemoglobin-NO and be transported to the muscle where it may be released as nitrosyl ion $\left(\mathrm{NO}^{+}\right)$and bind to reduced glutathione (GSH) to generate $\mathrm{GSNO}^{[36]}$. Such small molecule $S$-nitrosothiols (SNO) offer a scientifically more satisfying way to view the preservation of the signaling actions on NO since now the functional nitrosation of proteins by SNO may be coupled to the redox state of the cell coupling extracellular and intracellular mechanisms mediating contraction-relaxation.

Nitric oxide as Cys-NO can travel through the plasma membrane in this way as a second messenger and hence transduce stimuli and initiate responses in adjacent cells. Of the known $\mathrm{NO}-$ mediated reactions with biological materials, nitrosylation is the major form of protein modification under physiological conditions and constitutes an important signal transduction mechanism. S-Nitrosylation is the covalent attachment of NO to the sulfur moiety of cysteine. This chemical reaction constitutes a redox sensitive post-translational, reversible modification of protein in response to stimuli outside the cell ${ }^{[37]}$. Rather than free diffusion of NO from a NOS, S-nitrosylation allows for the compartmentation of the source of $\mathrm{NO}$ and the site of nitrosylation (Cysteine). The formation of SNOs is a critical pathway in the signaling of $\mathrm{NO}$ between cellular compartments since it maintains the availability of NO generated in one cell to act in another preserving the action of NO in time and space ${ }^{[38]}$. Small molecular weight SNOs such as Cys-NO and GSNO constitute the major determinants of subsequent transnitrosylation of target proteins to alter cellular response ${ }^{[39]}$ and cell-cell transfer of NO.

Once accumulated in a target cell such as the uterine myocyte, GSNO may provide a source of both NO for protein transnitrosylation as well as glutathione for glutathionylation via the action of glutathione- $S$ transferase reactions ${ }^{[40]}$. Thus regulation of protein targets in myocytes such as membrane channels in a reversible fashion to activate or inactivate current may have profound influence on uterine quiescence. It is possible that actions of $\mathrm{NO}$ or glutathione may accumulate as a consequence of vascular NO generation and redox reactions in uterine myocytes that then manage contractile force. The notion that pregnancy physiology and preterm birth may in part involve an inflammatory-like state ${ }^{[41]}$ fits with this notion and provides a testable platform for these ideas.

Given then that NO nitrosylates one or more regulatory proteins in myometrial smooth muscle to produce relaxation, we developed a method for showing S-nitrosylation in whole tissue lysates. This method has allowed us to elucidate the human myometrial smooth muscle nitroproteome and to test the effect of these post-secondary modifications on relaxation. Our method, which we are calling Nitro-DIGE, selectively labels $S$-nitrosylated proteins in a cell extract using spectrally resolvable Alexa Fluor maleimide dyes. Labeled extracts are then analyzed using 2-dimensional difference gel electrophoresis (2D DIGE). With this powerful technique we can identify differences in levels of $S$-nitrosylation between term and preterm myometrium. These identified proteins are regulatory in nature and preliminary results have identified candidates such as heat shock protein beta-1, desmin, alpha actinin which have been shown to regulate contraction in smooth muscle tissue. Importantly, we have found nitrosylation of the K2P channel TREK-1 and confirmed the identity of this protein by LC-MS/ MS. Current work is directed at both hypothesis-directed examination of the function of nitrosylated TREK channels and the smooth muscle thin filament contraction-relaxation pathway, as well as identifying prominent proteins that are selectively nitrosylated by pregnancy progression and/or in response to experimental NO-stimulation of tissues in functional assays where relaxation/contraction can be correlated with protein nitrosylation.

\section{TRAAK-family channels}

Two-pore-domain $\mathrm{K}^{+}(\mathrm{K} 2 \mathrm{P})$ channel subunits are made up of four transmembrane segments and two pore-forming domains that are arranged in tandem and function as either homo- or heterodimeric channels (Figure 1). This structural motif is associated with unique gating properties that would well serve quiescence in myometrium, including background channel activity (so-called leak current) and sensitivity to membrane stretch. Moreover, TRAAK-family K2P channels are modulated by cellular lipids and pharmacological agents, including polyunsaturated fatty acids such as arachidonic acid and volatile general anesthetics ${ }^{[42]}$. Acidity and heat have also been suggested to activate the channel ${ }^{[43,44]}$, while antipsychotics such as fluphenazine have been shown to block TREK-1 but not the related TRAAK channels ${ }^{[45]}$.

\section{Arachidonic acid and acidic pH in pregnancy myo- metrium}

Blood flow is temporarily compromised during forceful uterine contractions during labor ${ }^{[46]}$. This transient ischemia is associated with intracellular acidosis and has been proffered as a mechanism for contractile regulation in myometrium ${ }^{[47]}$. Myocyte signaling domains may be acidic on the basis of their construction per se, independent of relative ischemia ${ }^{[48]}$. Relative acidification at the myocyte membrane activating TREK-1 during gestation would fit with hyperpolarization of the membrane and decreased uterine activity. An abundance of 


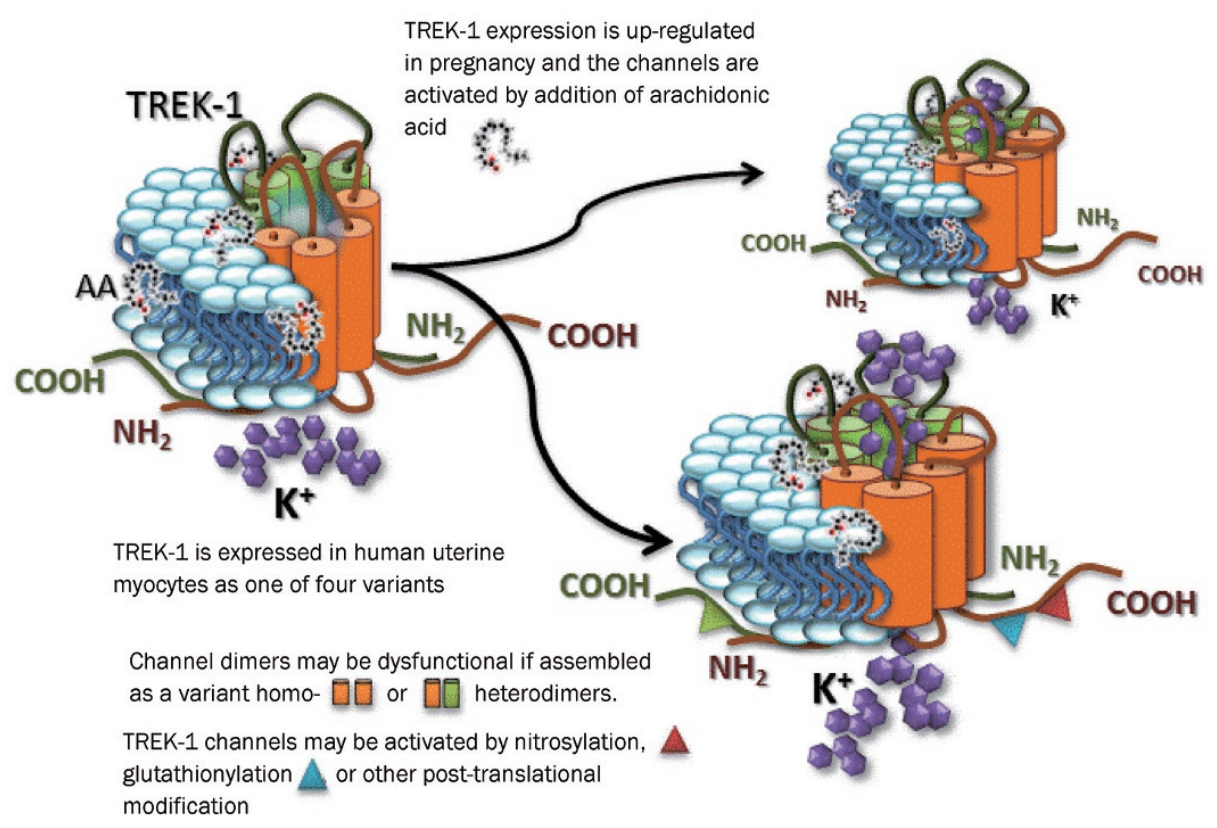

Figure 1. TREK-1 concept. Pregnancy results in up-regulation of channel number and provides for activation by stretch (right-hand figures) and arachidonic acid. The presence of channel variants (depicted as 2, 4-transmembrane units of disparate color) could result in assembly of channels that exhibit altered function or are dysfunctional. Altered conductance may be accompanied by disparate activation characteristics. Posttranslational alteration by nitrosylation, glutathionylation and or phosphorylation may confer sites of disparate regulation in preterm labor. Multimodal activation by stretch, heat, depolarization, intracellular acidosis, lipids and volatile anesthetics has been reviewed ${ }^{[42]}$. TREK-1 is tonically inhibited by the actin cytoskeleton opening the possibility that pregnancy releases such inhibition through cytoskeletal reorganization. Protonation of a glutamic acid residue within the C-terminus of TREK-1 increases the affinity of this domain for inner leaflet phospholipids and increases activity. Stimulation of Gq-coupled extracellular receptors can inhibit TREK-1. A variety of possibilities for regulation of the TREK-1 channel in the uterine myocyte suggests that studies of TREK-1 may reveal a therapeutic target for preterm labor.

arachidonic acid in pregnant myometrium ${ }^{[49]}$ also would signal TREK-1 activation. Together, these influences may contribute to gestational uterine quiescence.

\section{TREK-1}

Other than our description of TREK-1 channels in human myometrium in $2005^{[50]}$ and the work of Bai et al in the same year $^{[51]}$, very little was known about these channels in the myometrium until recently. Despite early claims that little TREK-1 was expressed in human ${ }^{[52]}$ or that no expression could be seen in mouse ${ }^{[53]}$ myometrium, we have shown the importance of these channels in human myometrium ${ }^{[50,54]}$. Recent studies in mice have now also appeared ${ }^{[55]}$. Electrophysiological currents can readily be measured in human uterine myocytes as well as cells overexpressing the human protein (Figure 2). These currents are recorded under conditions that block other potassium channels and are themselves blocked by fluphenazine underscoring their identity as TREK-1 currents. Our ability to determine channel expression and functionally measure these channels in freshly isolated myocytes as well as cells overexpressing cloned channels, permits a thorough examination of the possibility that genetic channel variants underlie cases of preterm labor in women.

Recent in vivo studies have shown that TREK-1 has a key role in anesthesia, neuroprotection, pain, depression ${ }^{[56]}$, and vascular regulation ${ }^{[57]}$. Since it is known in rat heart that TREK-1 splice variants result in two different operating modes of the channel ${ }^{[58]}$, and since channel dysfunction could correlate with early labor, we tested the hypothesis that TREK-1 in human myometrium may also be alternatively spliced. We are aware that other data is available, describing TREK-1 variants associated with failure to respond to antidepressants ${ }^{[56]}$ and a variant in rat brain that is thought to code for a channel by alternative translation initiation that is permeable to both $\mathrm{Na}^{+}$and $\mathrm{K}^{+}$ions ${ }^{[59]}$. Such a channel, if expressed in human myometrium, could readily depolarize the cell based on the $\mathrm{Na}^{+}$gradient and contribute to early initiation of labor. Thus, a careful examination of TREK-1 regulation in human myometrium is particularly important.

\section{TREK-1 variant expression}

Because TREK-1 gene expression is regulated by pregnancy increasing at term and falling at the time of labor ${ }^{[54]}$, it stands to reason that TREK-1 could be important in regulating relaxation until labor and may or may not participate in the intercontractile period during labor as suggested by the continued presence of the protein during the laboring period. If TREK-1 currents activated by the biochemistry of pregnancy (eg, progesterone dominance, arachidonic acid production) are important in uterine quiescence, then dysfunctional channels or low- 
A

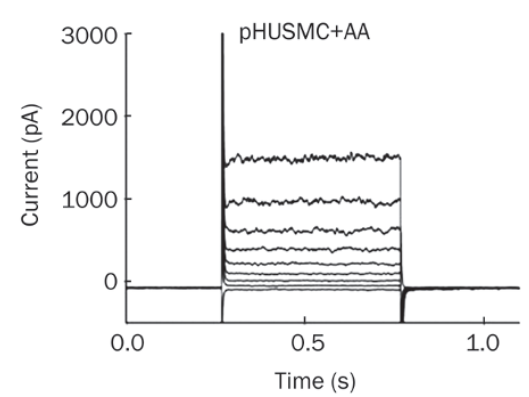

B

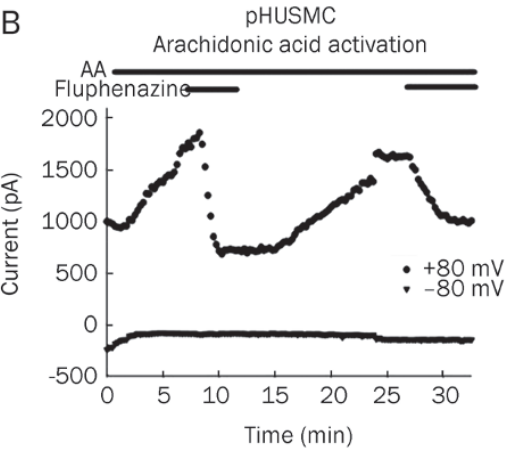

C

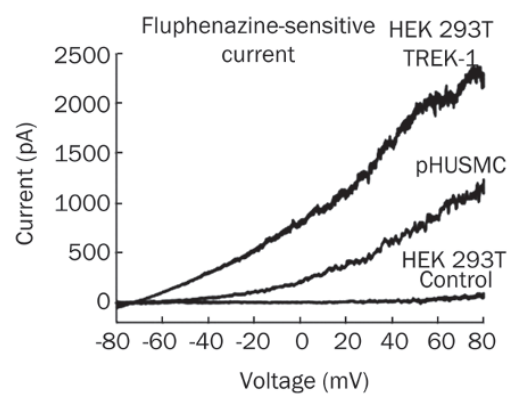

Figure 2. TEA-insensitive $\mathrm{K}^{+}$current in isolated uterine myocytes from gravid myometrium. (A) Whole cell currents elicited by voltage steps (-80 to $+80 \mathrm{mV}$ ) under $10 \mu \mathrm{mol} / \mathrm{L}$ arachidonic acid (AA). (B) Whole cell current activated by $10 \mu \mathrm{mol} / \mathrm{L}$ AA and blocked by $10 \mu \mathrm{mol} / \mathrm{L}$ fluphenazine. (C) Fluphenazine-sensitive, AA-activated whole cell currents (AA-AA+Fluphenazine) elicited by $1 \mathrm{~s}$ voltage ramps (reversal potential $\approx-70 \mathrm{mV}$ for HEK $293 \mathrm{~T}$ (human embryonic kidney) cells over expressing human TREK-1 and isolated pregnant myocytes [pHUSMC] indicates $\mathrm{K}^{+}$current).

ered TREK-1 expression could underlie cases of spontaneous PTL. We found a high level of variation between samples in the extreme $5^{\prime}$-end of the mRNA.

We identified TREK-1 splice variants in human myometrium (Figure 3) using PCR. We have now cloned each of these putative channels and are expressing them in HEK cells in order to perform electrophysiological measurement of TREK-1 currents that we have examined in isolated uterine myocytes. The variability of expression differences including samples (patients) that express only one variant of the channel such as several of the preterm laboring samples we have collected, suggests the possibility that functional correlations between TREK-1 channel variants and TREK-1 variant channel function will be possible for human TREK-1. Human brain (hB) was amplified as a positive control and expressed only one of the variants seen (a, as expected) in one or more myometrial samples. This is exciting because it suggests a tissue-specific regulated expression is likely in myometrium and may have functional significance. We have tentatively named these variant transcripts from myometrium $\alpha, \beta, \gamma, \delta$ (Figure 3 ). The possibility that each of these $(\beta, \gamma, \delta)$ corresponds to an expressed channel is being pursued.
Whatever the final outcome of preterm labor research, there is not a more significant human research imperative than to understand and prevent preterm delivery. If one considers the energy and treasure we expend on studying diseases of the aged only to cripple our healthcare systems with expensive medications and technology for the last years of life, and contrasts this with the relative ignorance we share about the beginning of life, it is possible to imagine we are failing. It is well past time to make preventing premature birth a priority.

\section{Acknowledgements}

Project was supported by National Institutes of Health (NIH) grant HD053028 and March of Dimes Prematurity Research Initiative \#21-FY10-176 to ILOB.

\section{References}

1 Beck S, Wojdyla D, Say L, Betran AP, Merialdi M, Requejo JH, et al. The worldwide incidence of preterm birth: a systematic review of maternal mortality and morbidity. Bull World Health Organ 2010; 88: 31-8.

2 Kinney MV, Kerber KJ, Black RE, Cohen B, Nkrumah F, Coovadia H, et al. Sub-Saharan Africa's mothers, newborns, and children: where and why do they die? PLoS Med 2010; 7: e1000294.

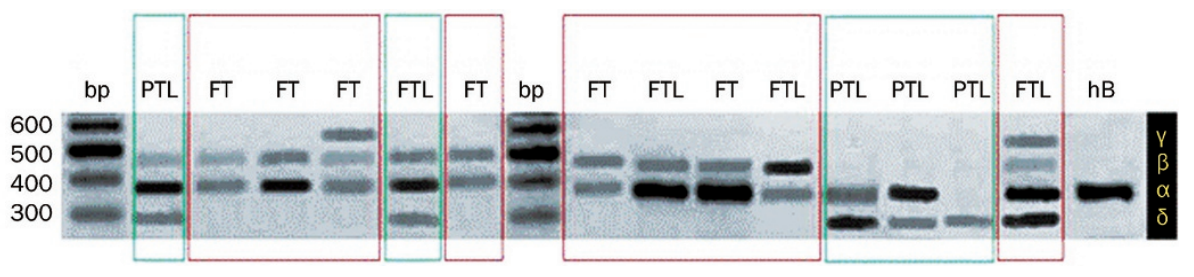

Figure 3. Expression of TREK-1 variants in human pregnant myometrium. We used the GenBank accession sequence NT_021877.18 to generate forward [AGG AAA CAG TAT GGG ACG ATG GCT] and reverse primers [CTG CTC CAA TGC TTT GAA CAC GGT] to examine expression of KCNK2 (K2P) TREK1 in myometrium. The predicted product was $373 \mathrm{bp}$. Tissues from women who were in spontaneous preterm labor (PTL); at full term (38-41 weeks) but not in labor (FT); or who were at full term in labor (FTL) were collected under informed consent. A composite gel from several experiments is shown. Human brain cDNA was employed as a positive control $(\mathrm{hB})$ and non-template controls run with water instead of cDNA were included with each experiment and verified the PCR (not shown). $\alpha-\delta$ are a tentative identification by our lab of unique channel variants in myometrium based on these experiments. These variants have now been cloned and expressed in human embryonic kidney cells for electrophysiological and signal transduction studies. 
3 Scotti N, Buonaguro L, Tornesello ML, Cardi T, Buonaguro FM. Plant-based anti-HIV-1 strategies: vaccine molecules and antiviral approaches. Expert Rev Vaccines 2010; 9: 925-36.

4 Haase EB, Buchman J, Tietz AE, Schramm LP. Pregnancy-induced uterine neuronal degeneration in the rat. Cell Tissue Res 1997; 288 : 293-306.

5 Latini C, Frontini A, Morroni M, Marzioni D, Castellucci M, Smith PG. Remodeling of uterine innervation. Cell Tissue Res 2008; 334: 1-6.

6 Majzoub JA, Karalis KP. Placental corticotropin-releasing hormone: function and regulation. Am J Obstetr Gynecol 1999; 180: S242-6.

7 Petraglia F, Giardino L, Coukos G, Calza L, Vale W, Genazzani AR. Corticotropin-releasing factor and parturition: plasma and amniotic fluid levels and placental binding sites. Obstetr Gynecol 1990; 75: 784-9.

8 Majzoub JA, McGregor JA, Lockwood CJ, Smith R, Taggart MS, Schulkin J. A central theory of preterm and term labor: putative role for corticotropin-releasing hormone. Am J Obstetr Gynecol 1999; 180: S232-41.

9 Challis JRG, Matthews SG, Gibb W, Lye SJ. Endocrine and paracrine regulation of birth at term and preterm. Endocr Rev 2000; 21: 51450.

10 Arthur P, Taggart MJ, Zielnik B, Wong S, Mitchell BF. Relationship between gene expression and function of uterotonic systems in the rat during gestation, uterine activation and both term and preterm labour. J Physiol 2008; 586: 6063-76.

11 Csapo Al, Wiest WG. An examination of the quantitative relationship between progesterone and the maintenance of pregnancy. Endocrinology 1969; 85: 735-46.

12 Mitchell BF, Challis JR, Lukash L. Progesterone synthesis by human amnion, chorion, and decidua at term. Am J Obstet Gynecol 1987; 157: 349-53.

13 Mitchell BF, Taggart MJ. Are animal models relevant to key aspects of human parturition? Am J Physiol Regul Integr Comp Physiol 2009; 297: R525-45.

14 Rittenberg C, Newman RB, Istwan NB, Rhea DJ, Stanziano GJ. Preterm birth prevention by 17 alpha-hydroxyprogesterone caproate vs daily nursing surveillance. J Reprod Med 2009; 54: 47-52.

15 Anderson AB, Turnbull AC, Murray AM. The relationship between amniotic fluid pressure and uterine wall tension in pregnancy. Am J Obstet Gynecol 1967; 97: 992-7.

16 Scudiero R, Khoshnood B, Pryde PG, Lee KS, Wall S, Mittendorf R. Perinatal death and tocolytic magnesium sulfate. Obstet Gynecol 2000; 96: 178-82.

17 Challis JR, Lye SJ, Gibb W, Whittle W, Patel F, Alfaidy N. Understanding preterm labor. Ann NY Acad Sci 2001; 943: 225-34.

18 Hertelendy F, Zakar T. Regulation of myometrial smooth muscle functions. Curr Pharm Des 2004; 10: 2499-517.

19 Buxton IL. Regulation of uterine function: a biochemical conundrum in the regulation of smooth muscle relaxation. Mol Pharmacol 2004; 65: 1051-9.

20 Husslein P, Fuchs AR, Fuchs F. Oxytocin and the initiation of human parturition I. Prostaglandin release during induction of labor by oxytocin. Am J Obstet Gynecol 1981; 141: 688-93.

21 Lin CH, Lin SY, Shyu MK, Chen SU, Lee CN. Randomized trial of oxytocin antagonist atosiban versus beta-adrenergic agonists in the treatment of spontaneous preterm labor in Taiwanese women. J Formos Med Assoc 2009; 108: 493-501.

22 Lamont RF. The development and introduction of anti-oxytocic tocolytics. BJOG 2003; 110: 108-12.

23 Kamel RM. The onset of human parturition. Arch Gynecol Obstet 2010; 281: 975-82.
24 Buxton IL, Kaiser RA, Malmquist NA, Tichenor S. NO-induced relaxation of labouring and non-labouring human myometrium is not mediated by cyclic GMP. Br J Pharamcol 2001; 134: 206-14.

25 Furchgott RF. Endothelium-derived relaxing factor: discovery, early studies, and identification as nitric oxide. BiosciRep 1999; 19: 235 51.

26 Kuenzli KA, Bradley ME, Buxton IL. Cyclic GMP-independent effects of nitric oxide on guinea-pig uterine contractility. Br J Pharmacol 1996; 119: 737-43.

27 Kuenzli KA, Buxton IL, Bradley ME. Nitric oxide regulation of monkey myometrial contractility. Br J Pharmacol 1998; 124: 63-8.

28 Bradley KK, Buxton IL, Barber JE, McGaw T, Bradley ME. Nitric oxide relaxes human myometrium by a cGMP-independent mechanism. Am J Physiol 1998; 275: C1668-73.

29 Buxton IL, Milton D, Barnett S, Tichenor SD. Agonist-specific compartmentation of cGMP action in guinea pig myometrium. J Pharmacol Exp Ther 2010: 335: 256-63.

30 Diamond J. Lack of correlation between cyclic GMP elevation and relaxation of nonvascular smooth muscle by nitroglycerin, nitroprusside, hydroxylamine and sodium azide. J Pharmacol Exp Ther 1983; 225: 422-6.

31 Diamond J, Hartle DK. Cyclic nucleotide levels during spontaneous uterine contractions. Can J Physiol Pharmacol 1974; 52: 763-67.

32 Hennan JK, Diamond J. Evidence that spontaneous contractile activity in the rat myometrium is not inhibited by NO-mediated increases in tissue levels of cyclic GMP. Br J Pharamcol 1998; 123: 959-67.

33 Aguilar HN, Mitchell BF. Physiological pathways and molecular mechanisms regulating uterine contractility. Hum Reprod Update 2010; 16: 725-44.

34 Suzuki T, Mori C, Yoshikawa H, Miyazaki Y, Kansaku N, Tanaka K, et al. Changes in nitric oxide production levels and expression of nitric oxide synthase isoforms in the rat uterus during pregnancy. Biosci Biotechnol Biochem 2009; 73: 2163-6.

35 Poniedzialek-Czajkowska E, Marciniak B, Kimber-Trojnar Z, Leszczynska-Gorzelak B, Oleszczuk J. Nitric oxide in normal and preeclamptic pregnancy. Curr Pharm Biotechnol 2011; 12: 743-9.

36 Allen BW, Demchenko IT, Piantadosi CA. Two faces of nitric oxide: implications for cellular mechanisms of oxygen toxicity. J Appl Physiol 2009; 106: 662-7.

37 Hess DT, Matsumoto A, Kim So, Marshall HE, Stamler JS. Protein S-nitrosylation: purview and parameters. Nat Rev Mol Cell Biol 2005; 6: $150-66$

38 Matsumoto A, Gow AJ. Membrane transfer of S-nitrosothiols. Nitric Oxide 2011 Mar 4 [Epub ahead of print].

39 Liu L, Yan Y, Zeng M, Zhang J, Hanes MA, Ahearn G, et al. Essential roles of S-nitrosothiols in vascular homeostasis and endotoxic shock. Cell 2004; 116: 617-28.

40 Laborde E. Glutathione transferases as mediators of signaling pathways involved in cell proliferation and cell death. Cell Death Differ 2010; 17: 1373-80.

41 Wei SQ, Fraser W, Luo ZC. Inflammatory cytokines and spontaneous preterm birth in asymptomatic women: a systematic review. Obstet Gynecol 2010; 116: 393-401.

42 Dedman A, Sharif-Naeini R, Folgering JH, Duprat F, Patel A, Honore E. The mechano-gated K(2P) channel TREK-1. Eur Biophys J 2009; 38: 293-303.

43 Goldstein SA, Bockenhauer D, O'Kelly I, Zilberberg N. Potassium leak channels and the KCNK family of two-P-domain subunits. Nat Rev Neurosci 2001; 2: 175-84.

44 Cohen A, Ben-Abu Y, Hen S, Zilberberg N. A novel mechanism for human K2P2.1 channel gating. Facilitation of C-type gating by 
protonation of extracellular histidine residues. J Biol Chem 2008; 283: $19448-55$.

45 Thummler S, Duprat F, Lazdunski M. Antipsychotics inhibit TREK but not TRAAK channels. Biochem Biophys Res Commun 2007; 354: 284-9.

46 Greiss FC Jr. Effect of labor on uterine blood flow. Observations on gravid ewes. Am J Obstet Gynecol 1965; 93: 917-23.

47 Larcombe-McDouall J, Buttell N, Harrison N, Wray S. In vivo pH and metabolite changes during a single contraction in rat uterine smooth muscle. J Physiol 1999; 518: 783-90.

48 Anderson RG. The caveolae membrane system. Annu Rev Biochem 1998; 67: 199-225.

49 Egarter $\mathrm{CH}$, Husslein P. Biochemistry of myometrial contractility. Baillieres Clin Obstet Gynaecol 1992; 6: 755-69.

50 Tichenor JN, Hansen ET, Buxton IL. Expression of stretch-activated potassium channels in human myometrium. Proc West Pharmacol Soc 2005; 48: 44-8.

51 Bai X, Bugg GJ, Greenwood SL, Glazier JD, Sibley CP, Baker PN, et al. Expression of TASK and TREK, two-pore domain $\mathrm{K}^{+}$channels, in human myometrium. Reproduction 2005; 129: 525-30.

52 Medhurst AD, Rennie G, Chapman CG, Meadows H, Duckworth MD, Kelsell RE, et al. Distribution analysis of human two pore domain potassium channels in tissues of the central nervous system and periphery. Brain Res Mol Brain Res 2001; 86: 101-14.
53 Koh SD, Monaghan K, Sergeant GP, Ro S, Walker RL, Sanders KM, et al. TREK-1 regulation by nitric oxide and CGMP-dependent protein kinase. An essential role in smooth muscle inhibitory neurotransmission. J Biol Chem 2001; 276: 44338-46.

54 Buxton ILO, Singer CA, Tichenor JN. Regulation of stretch-activated two-pore potassium channels in human myometrium in pregnancy and labor. PloS One 2010; 5: e12372.

55 Mongahan K, Baker SA, Dwyer L, Hatton WC, Park KS, Sanders KM, et al. The stretch-dependent potassium conductance TREK-1 and its function in murine myometrium. J Physiol 2011; 589: 1221-33.

56 Perlis RH, Moorjani P, Fagerness J, Purcell S, Trivedi MH, Fava M, et al. Pharmacogenetic analysis of genes implicated in rodent models of antidepressant response: association of TREK1 and treatment resistance in the STAR $\left({ }^{*}\right)$ D study. Neuropsychopharmacology 2008; 33: $2810-9$.

57 Bryan RM Jr, Joseph BK, Lloyd E, Rusch NJ. Starring TREK-1: the next generation of vascular $\mathrm{K}^{+}$channels. Circ Res 2007; 101: 119-21.

58 Xian TL, Dyachenko V, Zuzarte M, Putzke C, Preisig-Muller R, Isenberg $\mathrm{G}$, et al. The stretch-activated potassium channel TREK-1 in rat cardiac ventricular muscle. Cardiovasc Res 2006; 69: 86-97.

59 Thomas D, Plant LD, Wilkens CM, McCrossan ZA, Goldstein SA. Alternative translation initiation in rat brain yields $\mathrm{K} 2 \mathrm{P} 2.1$ potassium channels permeable to sodium. Neuron 2008; 58: 859-70. 